\title{
Problems and Solutions of Accounting Work in Enterprises
}

\author{
Shen Jinhai ${ }^{1, *}$ \\ ${ }^{1}$ School of business, Hohai University, Changzhou City, Jiangsu Province, China
}

\begin{abstract}
With the continuous development of economy, the importance of accounting work in enterprises has been gradually highlighted. Reasonable and effective enterprise accounting can not only provide impetus for the economic development of enterprises, but also ensure that the accounting system of Chinese enterprises becomes more perfect. Therefore, in the actual operation process, enterprises need to make a reasonable analysis of various problems existing in the current accounting work, to work out a feasible solution plan, and constantly innovate. In addition, the solutions will be truly implemented in the work, so as to ensure that the enterprise's accounting work can be carried out more reasonably and effectively, and provide certain support for the enterprise to achieve better development.
\end{abstract}

\section{Introduction}

With the advent of economic globalization, China's economic system is constantly developing in the direction of diversification and informatization, which not only ensures the rational reform of the economic system, but also promotes the further development of the national economy, and provides strong support for the construction of a harmonious socialist society in China. At present, due to the influence of various aspects, the accounting work has always been inadequate, which has a negative impact on the enterprise to obtain more benefits. Therefore, in order to ensure the long-term and healthy development of enterprises, it is necessary to analyze the problems existing in the current enterprise accounting work, and formulate practical solutions to ensure that enterprises can maximize economic benefits under the support of scientific and reasonable accounting work, and then achieve better development.

\section{Overview of modern accounting}

\subsection{Concepts}

With the continuous development of social economy, the accounting work of enterprises plays a very important role, mainly through the accountant to carry on the statistics, the calculation and the analysis to the accounting information, takes the currency as the unit of measurement, carries on the analysis to the enterprise in the production, the management process, then guarantees to be able to carry on the comprehensive understanding and the grasp to the enterprise actual situation. Reasonable and effective accounting work can not only guarantee the accuracy and authenticity of accounting information disclosure, but also provide certain support for enterprise management to make correct decisions, so as to ensure that enterprises can effectively control and manage the internal structure and operation situation [1].

\subsection{Characteristics}

At present, some enterprises in the actual work, due to the influence of various factors, such as the wrong understanding of accounting work by enterprise managers, do not understand the specific accounting work content and other reasons, leading to some more prominent problems in accounting work. And with the continuous development of society, a large amount of information can be accessed in accounting work, which leads to more and more prominent problems in accounting work, which embodies the following characteristics. First, because accounting work is mainly based on money as a dose unit for statistical work. Therefore, for the actual work can not use monetary statistics assets, can not be accurate, practical judgment, accounting work has incomplete problems. Second, the accounting work in most enterprises takes the voucher as the main accounting basis, and thinks that the authenticity of the voucher can guarantee the accuracy of the accounting work. However, if the certificate is modified, then the accounting information is not true, which is not consistent with China's current economic development requirements. Third, in the current accounting work, people need to have systematic, continuous and comprehensive ideas. In fact, the accounting system referred to in the actual work is not

\footnotetext{
* Corresponding author e-mail address: a85502899@qq.com
} 
without loopholes, so it will lead to some deficiencies in the accounting work of enterprises.

\section{Problems in Accounting in Enterprises}

\subsection{The accounting information is not true}

The current situation of accounting information fraud, information distortion is more serious, even has become a common phenomenon in many enterprises accounting work[2].

There are several main reasons leading to the untrue accounting information: first, the legal concept of enterprises is relatively thin, and there are often cases of illegal interference in accounting work; second, instructing or instructing accountants to modify data or falsifying accounting vouchers and accounting statements; third, accounting records are set up from time to time; fourth, the working environment of accountants is relatively poor, internal supervision does not play a real role, and the basic work of accounting and internal control work are relatively inadequate; and fifthly, the level of various false techniques is constantly improving, and accountants can not distinguish between true and false. These problems in enterprise accounting seriously affect the normal social order and harm the interests of enterprises.

\subsection{Lower quality of personnel}

In the era of knowledge economy, talent is the basic to ensure that enterprises can have good competitiveness, and it is also an important factor affecting the effectiveness of management. Because of the difference in concept and cognition, many enterprises have poor investment in accounting management, and the number of accountants is not in line with the needs of enterprise accounting work, which affects the work effect of accountants. Also increased the accountant's work pressure to a certain extent. In this case, some accountants will be idle, work enthusiasm has been seriously hit, resulting in financial work can not be carried out in a quality. At the same time, because the enterprise accounting work has very strong professionalism, the post quality request is also relatively high, the related personnel not only needs to have the good specialized knowledge, but also must have the certain summary ability, the thought ability and the practice ability, This puts forward more strict requirements for the quality of talents. According to the current situation of talent composition in enterprises, there are still some shortcomings in the cultivation of professional quality of talents.

\subsection{Poor risk awareness}

In some enterprises where the actual development situation is not mature enough and the capital involves a small amount, they will generally establish relatively broad specific development goals, pay too much attention to the actual interests of the enterprises, and do not analyze the various accounting risk factors that may occur. As a result, enterprises can not achieve better development. Fundamentally speaking, this is because the enterprise has not set up the correct accounting risk consciousness, but also a kind of performance that the enterprise development is not mature enough [3]. In this case, there are a variety of risks for enterprises, whether they invest in projects or produce products. Because most enterprises do not pay enough attention to this aspect of work, do not fully consider their own economic strength, each accounting business risk analysis, easy to cause more serious economic losses, to achieve sustainable development of enterprises is very unfavorable.

\section{The concrete method to solve the problem in the enterprise accounting work}

There are still many problems in the financial work of enterprises, we put forward some specific solutions in the following. Figure 1 shows the flow chart of enterprise financial work.

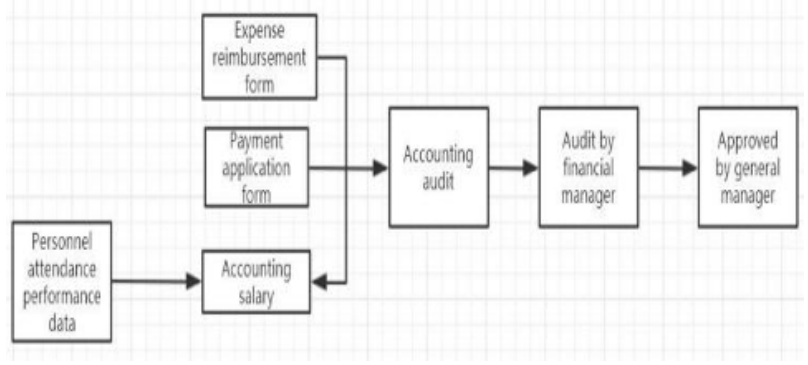

Figure 1. Enterprise financial work flow chart

\subsection{Ensure that the original documents are true and to prevent fraud}

In the accounting work, the original voucher is a very important accounting data, generally obtained and filled in when the economic business occurs or is completed, which can directly prove the occurrence and completion of the business, and is a written proof of the business. According to the relevant accounting standards, the original vouchers can not be illegally obtained or filled in. Once the original vouchers are forged, the accountants carry out the accounting work according to the untrue vouchers, which will lead to the failure to guarantee the authenticity of all subsequent accounting information. Therefore, in order to effectively avoid this situation in the accounting work of enterprises, first of all, it is necessary to make, fill in and record the original vouchers in accordance with the actual requirements of the original vouchers in the Accounting Law and the Accounting basic work Standard, and the original vouchers filled out by the business department should be handed over to the accountants in time, and the accounting department also 
needs to deal with the original vouchers according to the unified norms, and then enter the accounts after checking them correctly [4]. Secondly, for some original vouchers that meet the requirements of accounting work, it is necessary to prepare the accounting vouchers in time and to record them in the first place; for some illegal or untrue original vouchers, the accounting department and personnel have the right not to accept them and need to report the situation to the superior supervisor; for the original vouchers that are true and reasonable but incomplete, the accountant needs to return them to the unit where the original vouchers are filled in, and then formally handle the accounting procedures after they have been filled in correctly. Through this way, it can guarantee the authenticity, rationality and legitimacy of the original accounting vouchers from the source, provide accurate accounting information for the subsequent accounting processing work, and ensure the quality of accounting work.

\subsection{Strengthening political studies and improving the construction of professional ethics}

In the whole accounting work, accounting staff is an important part, its professional ability, professional accomplishment, moral quality, will have a certain impact on the whole accounting work. Therefore, in order to ensure that the accounting work of enterprises can be carried out in a more quality and efficient way, it is necessary to effectively strengthen the political learning of the current accounting department staff. So that the staff in the skilled professional skills at the same time, can enhance the ideological consciousness, to avoid the situation of illegal discipline.

First of all, it is necessary to carry on the ideological education to the accountant, through the training, the participation education activity and so on way, enables the accountant to set up the correct work idea, guarantees the accountant can guarantee the enterprise economy benign development as the first work goal, truly contributes a strength for the enterprise development. Secondly, in addition to ideological education, it is also necessary to ensure that accountants can not only pay attention to all kinds of complicated accounting affairs. Enterprises need to lead accountants to keep pace with the development of the times, update their working concepts and methods, and constantly learn new and efficient working models. Only in this way can accountants consciously integrate into the trend of social development and not lose their way. At the same time, as accountants, it is necessary to strictly abide by the various accounting systems issued by the state and implemented within the enterprise, strictly require themselves, act in accordance with the rules and regulations, carry out accounting work carefully and conscientiously, and perform the functions of financial supervision, thus ensuring that they can play a positive role in resisting and correcting unhealthy practices in accounting work, ensuring the safety of the accounting environment of enterprises, and providing support for enterprises to obtain more accurate and effective accounting information [5].

\subsection{Improve the work of team building and enhance the professional ability of personnel}

The professional ability of accountants can have a great impact on the quality of accounting work. Whether they have enthusiasm and enthusiasm for accounting work is also the basis of whether the accounting reform can realize the deep development. In order to ensure that the process of accounting reform can be promoted and the enterprise can develop actively, first of all, it is necessary to establish a reasonable mechanism for the training, selection and evaluation of accounting talents within the enterprise to enhance the professional enthusiasm of accountants. At the same time, it is necessary to improve the training of on-the-job accountants in enterprises and carry out onthe-job education activities through various forms, channels and levels. And under the unified planning goal of the financial department, ensure that different regions, different departments and school education participate in the on-the-job training of accounting. In addition, it is necessary to formulate a reasonable and effective professional standard of enterprise accounting, and improve the quality of internal accountants in an all-round way, so as to ensure that the quality of accountants can be improved in an all-round way by strengthening the construction of the contingent [6]. Secondly, it is necessary to establish a reasonable and effective incentive mechanism to integrate it into the daily management work of the financial department, and to formulate a reasonable and effective system for the promotion and promotion of accountants by assessing, evaluating, rewarding and punishing the professional ethics of accountants. Under the effective encouragement and restraint, the accountants can truly form the consciousness of serious work, create a positive atmosphere of accounting work, and cultivate more accounting talents with both moral and talent.

\subsection{Establishing an accounting supervision mechanism and strengthening the effect of internal and external supervision}

In order to ensure the effective implementation of various accounting measures, enterprises need to establish a reasonable and effective supervision mechanism, combine internal supervision with external supervision, and strengthen the actual effect of supervision. Ensure that accounting work can be carried out with quality and quantity [7]. First of all, the various departments in the enterprise need to improve the internal financial management mechanism of the enterprise, and clearly divide the responsibilities. At the same time, it is necessary to strengthen the internal control management of assets, establish and perfect the asset and material management system, and establish standardized operating procedures in all aspects of procurement, access and sales. Secondly, enterprises need to strengthen the effectiveness of external supervision, and combine it with internal control to supervise the actual operation of enterprises. In 
the aspect of accounting supervision, the supervision of the state and society belongs to the external supervision, and the way of the state supervision mainly includes the tax department, the bank, the industrial and commercial department, etc., which supervises the assets and economic situation of the enterprise in accordance with the relevant laws [8]. Social supervision mainly refers to some professional accounting institutions, such as various accounting firms, mainly through the form of third party entrustment, to audit the internal accounting work of enterprises, capital verification, etc. By effectively combining internal supervision with external supervision and strengthening the actual effect of supervision, the accounting work can be carried out more qualitatively under scientific and reasonable supervision, and provide certain support for the positive development of enterprises.

\section{Conclusions}

The quality of accounting work directly affects whether enterprises can achieve positive development, which plays a very important role in reasonable cost control and more economic benefits. Therefore, in order to ensure that the accounting work plays its due role more effectively, the most important thing for enterprises is to analyze the problems existing in the accounting work of enterprises, find out the causes of the problems, and formulate reasonable and effective solutions. Only in this way can enterprises obtain more economic benefits by perfecting accounting work and lay the foundation for the better development of our economy.

\section{REFERENCES}

1. Zhang Zhi. (2020) Analysis of Main Problems and Solutions in Enterprise Accounting Work. Corporate culture, 06:109-113.

2. Meng Xianglu. (2020) Discussion on the Problems and Solutions of Accounting Basic Work of Small and Medium-sized Enterprises in Brief. China's collective economy, 30:134-135.

3. Zhang Fengying. (2020) Problems and Solutions in Enterprise Accounting. Science and Wealth, 11:18.

4. Yang Pinghua. (2020) Discussion on the Problems and Solutions of Financial Accounting Supervision in Enterprises. Heilongjiang Science 10, 13:116-117.

5. Qin Li. (2020) Discussion on the Problems and Solutions Facing the Accounting Industry in Enterprises. Modern Business, 25:187-188.

6. Su Lili, Wang Xuejuan, Ma Yani. (2019) Discussion on Problems and Solutions in Financial Accounting Management of Small and Medium-sized Enterprises. Modern Economic Information, 01:283.
7. Liu Yang. (2017) Analysis of Main Problems and Solutions in Current Enterprise Accounting Work. Digital users, 09:105.

8. Pang Taixin. (2020) The problems and countermeasures of smes' accounting. Finance and Economics, 03:199. 